\title{
Design and Construction a Falling Water Digital Display System
}

\author{
Israa Subri Alfurati \\ Computer Engineering \\ Department \\ University of Basrah \\ Basrah, Iraq
}

\author{
Bayadir A. Issa \\ Southern Technical \\ University \\ University of Basrah \\ Basrah, Iraq
}

\author{
Osama T. Rashid \\ Computer Engineering \\ Department \\ Iraq University College \\ Basrah, Iraq
}

\author{
Abdulmuttalib T. \\ Rashid \\ Electrical Engineering \\ Department \\ University of Basrah \\ Basrah, Iraq
}

\begin{abstract}
Water fountains have been used for thousands of years for utilitarian and aesthetic purposes. Fountain design provides an excellent opportunity for multidisciplinary projects for engineering and art students. In this paper, a falling water system is designed for an indoor fountain with a special effect feature. This system produces letters of the alphabet, simple shapes, and symbols with water jets. A microcontroller is used and programmed to create and sequence through interesting arrangements of water displays. This paper offers the hardware and software parts of light fountain control system that adjusts the water heads. The fountain hardware system consists of Arduino MEGA 2560, relays, water valves, power supply to operate the electrical circuit, in addition to the iron structure of the presentation of the shapes. The software part consists of the visual basic language written in a PC device and C-Language written on Arduino device to control the falling water system. The experimental results are tested for different alphabetic words and graphical shapes.
\end{abstract}

\section{Keywords}

Falling Water, Fountains, Arduino microcontroller

\section{INTRODUCTION}

In the most recent years, individuals needs in the fields of stylish taste, and tender loving care has significantly changed. In the open-air furniture field, individuals require more specific highlights to make their spaces comfortable, livable and unique. This pattern has too influenced a traditional component of open-air decorations [1]. From that point forward fountains have been utilized for some reasons, for example, evaporative cooling in dry atmospheres, creating breathtaking water shows, filling in as a central the point in an urban setting, veiling traffic commotion, making mitigating sounds, and so forth. Among the most well-known fountains have been those that make embellishments, for example, astonishing individuals in water jokes, moving statues by streaming water, creating uncommon and energetic water planes, joining water and fire in sensational shows, and including music or potentially lighting [2]. Fountain refers to a framework where water is drawn from a source, fills a bowl of some sort, and is depleted away. Fountains might be detached or associated with dividers of structures. Fountains of water may stream over different kinds of surfaces: stone, concrete. Bowls may flood [3]. Fluid water is a remarkable substance. It is a deformable yet to a great extent incompressible. Because of its polar nature, water normally draws in itself, limiting surface vitality. This additionally enables it to be pulled in to electric charges. Albeit intrinsically non-conductive, most water contains pollutions that enable it to convey power. It is straightforward, permitting it to fill in as a light guide. Water has a high warmth limit and is thermally conductive. It conveys sound very well. For the reasons for experimentation, it is helpful that it is likewise modest, broadly accessible, non-harmful, and simple to sound [4]. The direct gush of a fountain now isn't enough, individuals need more and attempt a more noteworthy visual effect. On request to satisfy this need, particular creators have made the moving fountains (or melodic fountains), which consolidate water and light plays based on a replicated the music track. This new sort of furniture has gathered significant achievement as of late, making another and exceptionally requested field in the fountains' market. The most punctual record of fountains goes back to 4000 BC in Iran1. For a huge number of years the fountains were gravity nourished - either legitimately from a running fountain of water, for example, a river that was found at a higher elevation2, or from a holding tank fabricated simply behind the fountain. Straightforward gadgets were utilized in quick arrangements to give embellishments, for example, making sound and movement to spectators [5]. The principle of the fountain is to move water to make, and attractive water highlight shows. There are three fundamental considerations of a fountain; water source, display effects and pump. The initial step is to distinguish the water supply accessible. In the event that there is no common water supply, it must be misleadingly filled and refilled from the central conduit. When the water source has been resolved, the subsequent stage is to set the water into the movement, what's more, to locate the correct water show. After the showcase impact and example of spouts are resolved, the determination of the main thrust of that point pursues [6-8]. In this work we design a fountain used for the stylish and diversion, when drawing shapes, pictures just as drawing words by water beads, this will astonish the watcher for this craftsmanship. This venture utilizes a large number of them utilized for decoration and pull in vacationers when putting in open spots, and shopping centers, and travelers' inns, as well as houses, where draws in individuals and inclinations to see him.

In this paper the hardware and software parts of light fountain control system is designed and build using Arduino microcontroller, driver circuits and water valves. The software part consists of the visual basic language written in a PC device and C-Language written on Arduino device to control the falling water system. Section II deal with , section III and conclusion is explained in section IV.

\section{RELATED WORK}

Back in 1971, when Fontana made its first fountain, it was something spectacular, something that attracted people to just stand and watch. For today's standards, it was nothing special 
really, it wasn't even illuminated at night, but still, it was something worth admiring. Fountains have been around since the early Bronze Age in south-eastern Greece. These fountains have been attached on the springs and canals for drinking and bathing water for cities and villages. Over the years, they have become used as decorations in several regions besides being sources of water. By the end of the 19th century, many urban water fountains were constructed due to indoor plumbing became a standard feature. Gradually, fountains become seen as monuments to decorate the cities, for entertainment and honor cultural events. Recently, fountains have delightful features and some of these fountains work with the music by new technologies for processing musical sound signals [9]. The Pump Spark Fountain Development Kit is a prototyping tool that allows non-experts to quickly create complex systems. It was inspired by the success of other hardware development systems such as Arduino, Gadgeteer, and Parallax's Basic Stamp [10 - 12]. These have empowered many to focus on the larger system design, rather than implementation details. Currently, those that wish to explore fluidic interfaces have no option but to immerse themselves in the tasks of selecting pumps, plumbing accessories and appropriate control systems. Many will be disappointed when they realize that pumps with internally controlled brushless motors are not compatible with standard motor controllers. We are in the process of arranging to make the Pump Spark kit commercially available to enable others to innovate in the creation of fluidic user interfaces. While it is not the intent of this work to provide a detailed review of fluidic interfaces, it is instructive to consider some examples. Arguably, the most famous water-display is that at the Bellagio Hotel in Las Vegas, Nevada [13]. This 8-acre fountain was created by Wet Design, and features highly choreographed water movements, sound and light. Disney's World of Color show at Disney California Adventure [14], another immensely popular water-based show, adds fire, projection, and a variety of other effects. Fluids are also often used to create ephemeral user interfaces [15]. These are interfaces that may last only a moment, such as text made from falling water, rising bubbles, or a momentary soap bubble. Examples include Space Printer [16], Bit. Fall [17], the Information Percolator [18], and Soap Bubble Interface [19]. Explorations have also taken advantage of the properties of water for indoor and outdoor gaming. Water Games [20] encouraged children to play together. In order to actuate a fountain, the children had to hold hands in a circle, and then rotate around the fountain. Water Ball Z [21] allowed kids and young adults to 'fight' each other in a virtual world using water streams to provide physical feedback without a wearable device. Casual Profanity [22] has shown a number of fluid sculptures. These use carefully woven, clear tubing, with segments of liquid pumped through. The effect is that of segments rapidly chasing as if through a maze. Submerging Technologies [23] consisted of three interactive water sculptures, each of which fundamentally used the water itself as the sensing element. The Tantalus fountain used water as a capacitive proximity detector to withdraw from an approaching hand. The Aqua-Harp and Touch Pond detected frustrated total internal reflection in a water waveguide, and reacted with sound and light respectively. A later project, Touch's [24], further explored the use of capacitive sensing in water. Water Touch [25] also uses a water waveguide, but adds depth information by using a camera to see the depth of finger penetration into the water. Aqua Top [26] turned water into an interactive surface display where users can interact with information projected on the water without using any electronic devices. A number of displays making use of water as a diffuser have also been proposed for entertainment and virtual reality [27]. Finally, Mann is well known for his waterbased, musical instruments. These include the Hyalophane [28] and the Water Hammer Piano [29]. In these instruments, interaction with the water creates the resonators that in turn produce the tones.

\section{SOFTWARE IMPLEMENTATION OF A WATERFALL GRAPHIC DISPLAY SYSTEM}

In this section the waterfall display system is implemented on computer using the visual basic program. This program is designed to simulate the principle of the waterfall display system working and also to switch on and also to switch off 24 valves used in hardware part of the system. This system is designed in order to study the relationship between the water fall speed and the appearance of the graphical shapes and the messages and also, to enhance the inter terminate and the appearance of the fountain in different forms of graphical shapes and messages. Fig. 1 shows the graphical shape for the user interface unit of the designed system. In the graphical user interface unit we found two ListBoxes: the right one contain some words represent some graphical shapes and some words to be display on the system and the left ListBox is used to display the chosen words from the right List Box. The words in left ListBox represent the current display graphical shape and words. Between the two list Boxes we found group of control tools. The first one is a ComboBox used to choose the current speed for the water fall. The Add Button is used to add any select word from right ListBox to the left ListBox. The Remove Button is used to delete any select word from the left ListBox. The View Button is used to simulate the water fall by displaying the graphical shapes and words in the Left Black screen. These shapes and words are display as red dots move down in the black screen. The Exit Button is used to close the application. The RUN Button is used to control turn on and turn off the 24 valves in the system according to the movement of the graphical shapes and the words in left black screen.

The software used to simulate the water fall in hardware part of the system is written according to the following steps:

1. Make a copy to any words from the right ListBox (graphical shapes or words) by selecting the chosen word and press the Add Button.

2. Press View Button to display the chosen graphical shapes and words in the left black screen. The principle of displaying in the black screen is simulate the water fall in the hardware part of the system.

3. Press RUN Button to manipulate the chosen words and sent the information byte by byte to 24 valve in hardware part of the system.

Fig. 2 shows the flow chart for the algorithm that implemented when press on the View Button and Fig. 3 shows the flow chart for the algorithm that implemented when press on the RUN Button. 


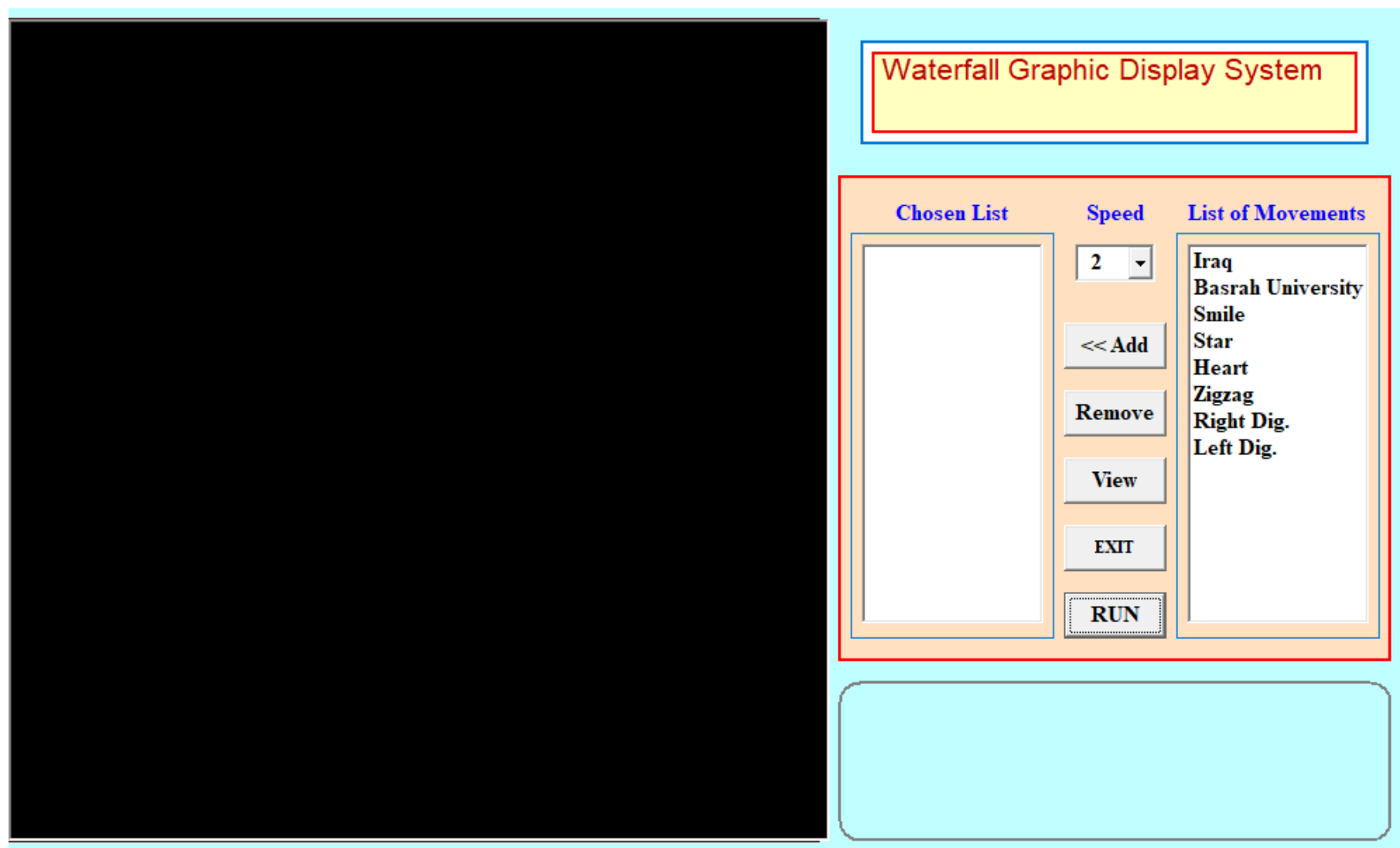

Fig.1. A graphical user interface unit (GUI) for the waterfall display system. 


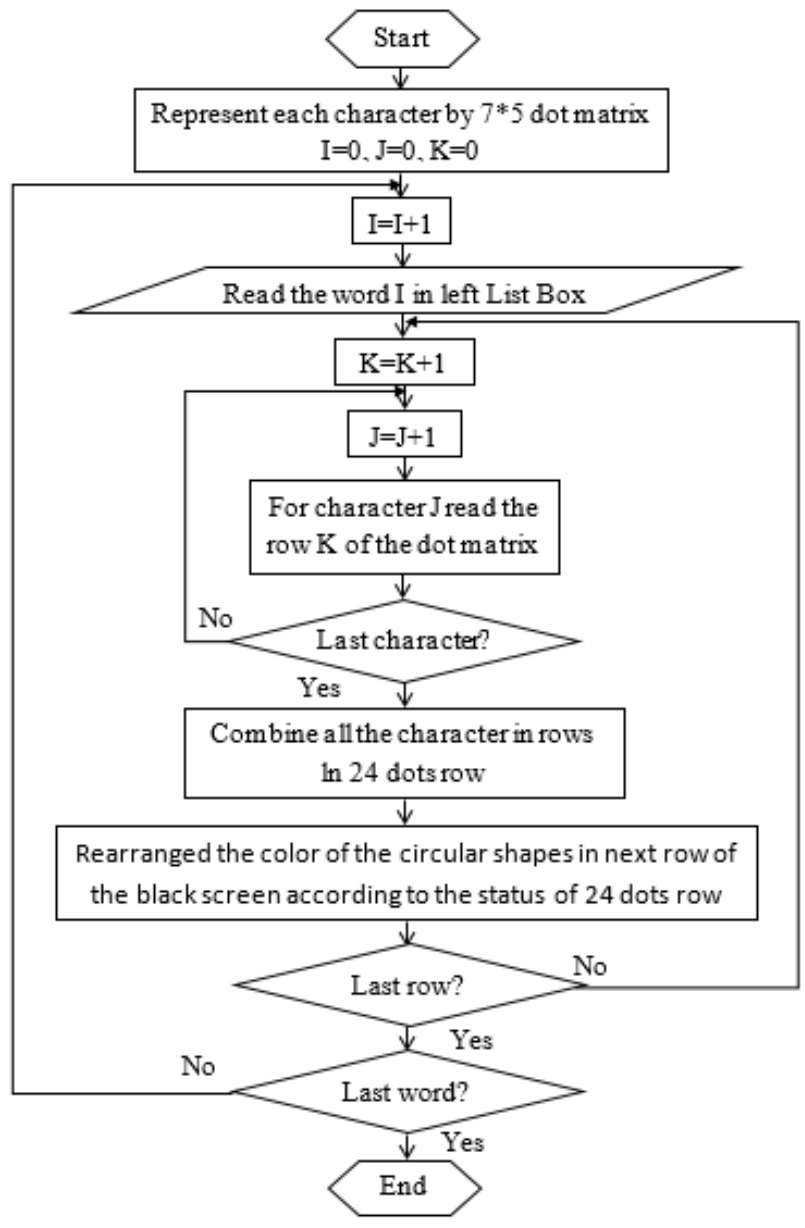

Fig.2. The flow chart that simulate the water fall in hardware part.

\section{HARDWARE IMPLEMENTATION OF A WATERFALL GRAPHIC DISPLAY SYSTEM}

This section describes the design and structure the hardware part of the waterfall graphical display system. Fig. 4 shows the block diagram of the designed system. This diagram consist of several stages: The software part, the Arduino microcontroller, the relay driver and the valves.

The software part is discussed in last section and the control program is written in visual basic language. Fig. 3 shows the flow chart for this program. This software manipulate the chosen word and supply the data to the microcontroller in Binary format.

The Arduino microcontroller (Mega 2560) is programed using C Language to receive the data supply by the computer through the USB port. This microcontroller is connected to relay modules ( 24 Relays) through the digital I/O ports. The data sent from microcontroller to relays is programmed according the shapes that want to display by the falling water.

Each relay in the relay module is connected to one valve through 5 volt supply. The switching on and of the 24 valves lead to display the falling water in discrete form which represent the shape of the word that want to show by the water.

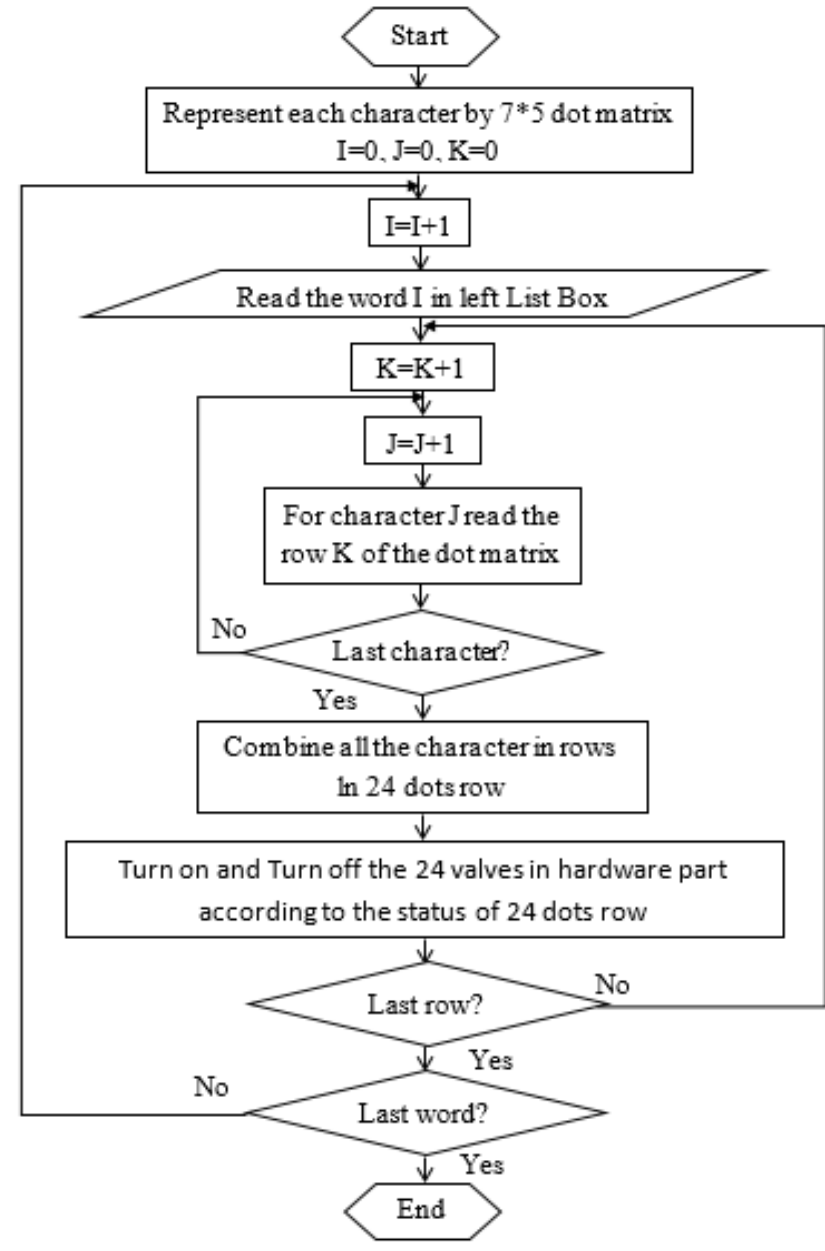

Fig.3. The flow chart of program that control the working of the 24 valves in hardware part.

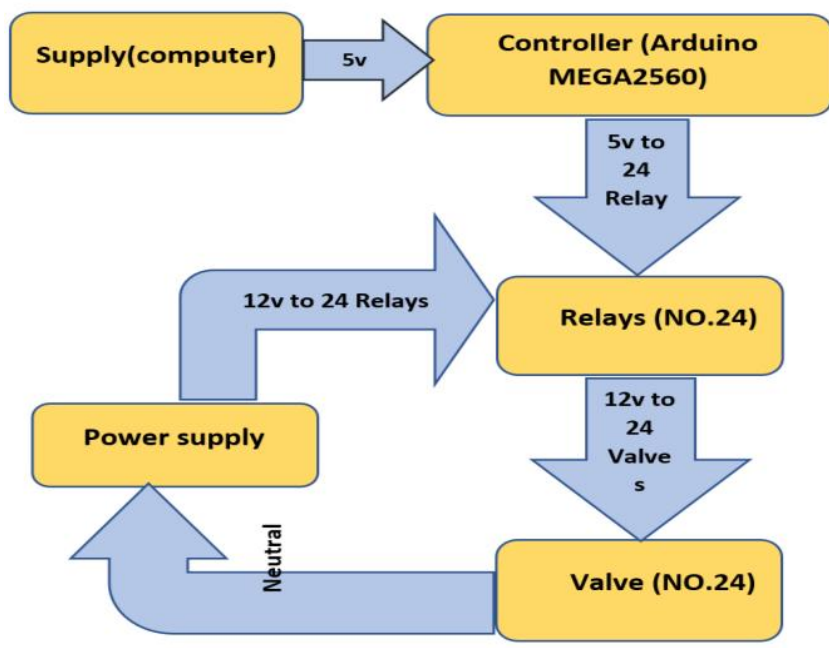

Fig.4. the Main Control diagram of the different components

The hardware part of the waterfall graphical display system has two parts: the mechanical structure and the main control board.

A. The mechanical Structure of the Fountain

The mechanical structure is designed to give a good view to the graphical shapes and words formed from the falling water. 
This structure consists of iron (Fig. 5), designed in height (200 $\mathrm{cm}$ ) in order to display the shapes in a good view and designed in the width $(160 \mathrm{~cm})$ in order to carry (24 valves) on a regular basis. This structure has two tanksL one at the basis is used to store the falling water and the other at the top of the system to supply the valves by the water. An electrical bump is used to cyclic the water from the down tank to the upper one.

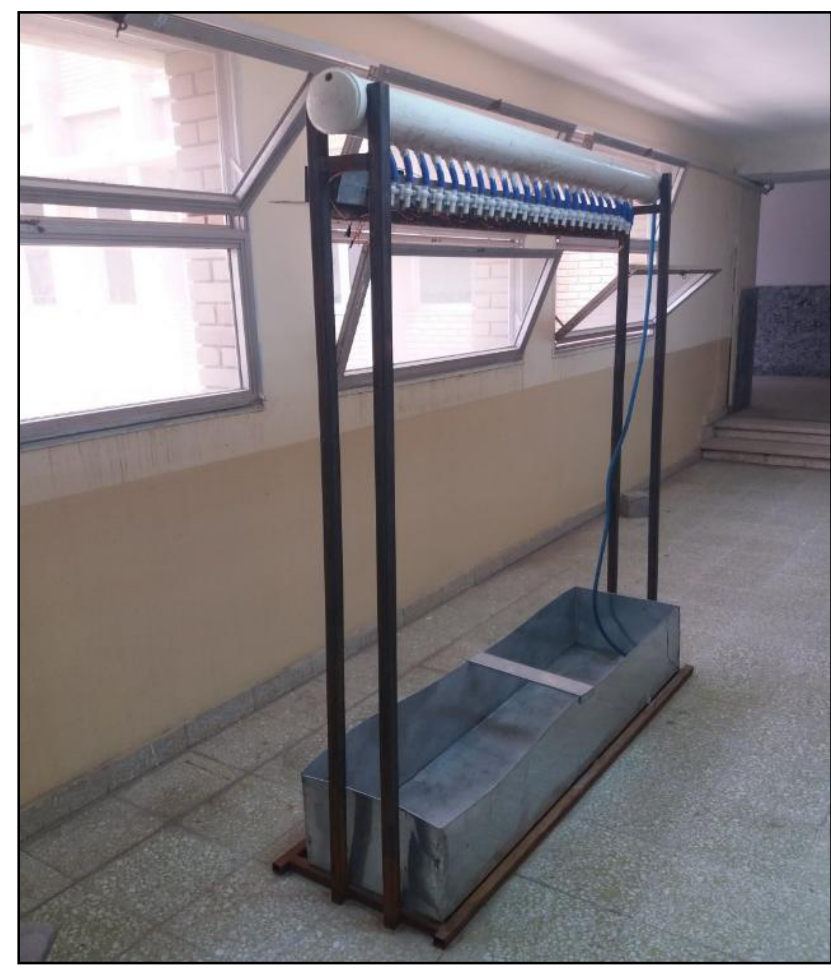

Fig.5. the iron structure with its valves.

\section{B. The Main Control Board}

Control of the presentation of shapes and symbols and other devices through the Arduino (MEGA 2560), where the Arduino is pre-programmed by linking it with visual basic language. Fig.6 shows the diagram of the different components of the main group, with Arduino control being the brain of the project. It receives and manipulates the information received from the computer and transmits the manipulate data to the relays in the form of a logical indication to control the opening and closing of the valves connected with the relays. The flow chart for the Arduino microcontroller program is shown in Fig. 7.The schematic diagram to the main control unit is shown in Fig.8.

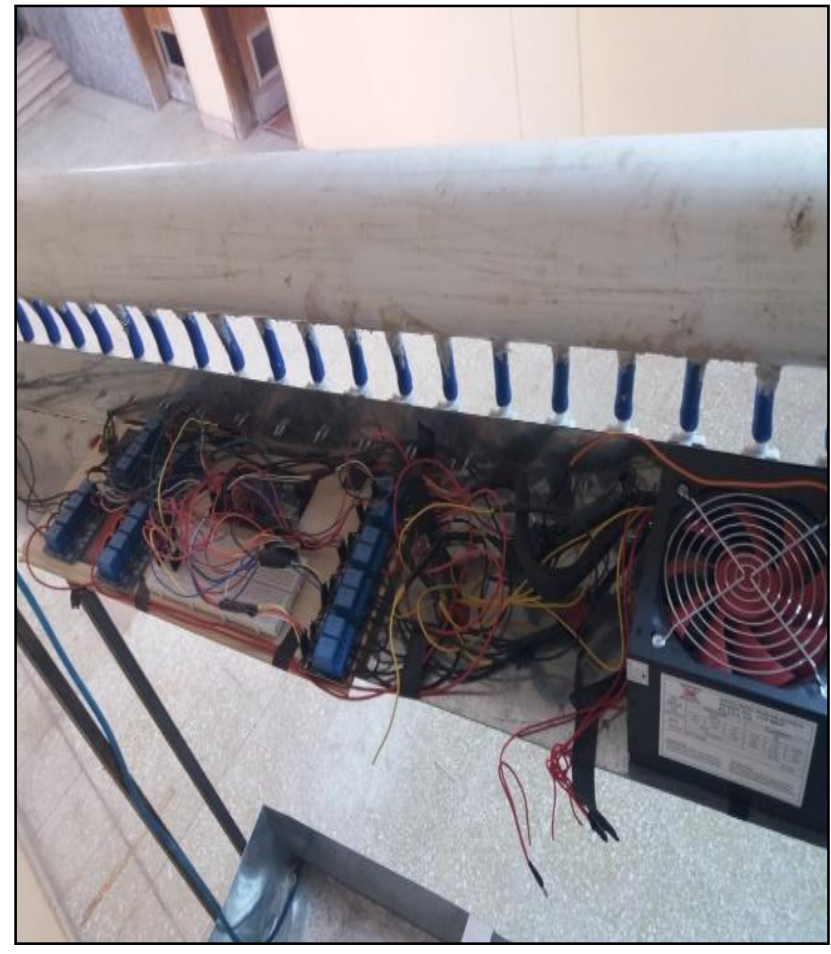

Fig.6.the internal design of the iron structure of fountain.

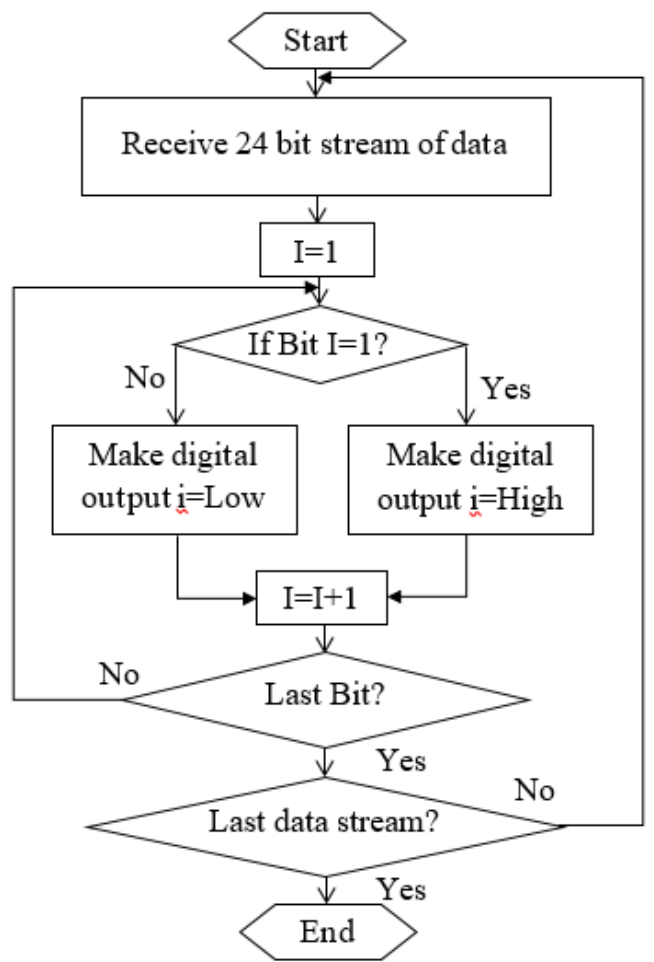

Fig.6.The algorithm of working the fountain.

\section{SIMULATION RESULTS}

The design and implementation of a fountain graphic display system is introduced using Arduino microcontroller, relays and valves in hardware part and the microcomputer with visual basic program as the software part. To enhance the display of falling water a graphical user interface GUI system is designed in microcomputer to arrange the display of the graphical shapes and words in a beautiful manner. The designed fountain project consists of several graphical shapes 
and word programmed to display in any sequence using the water fall principle. Fig. 8 shows the first simulation to display the steps of viewing the word IRAQ. Also Fig. 9 shows the same principle in displaying the graphical shape of the star.

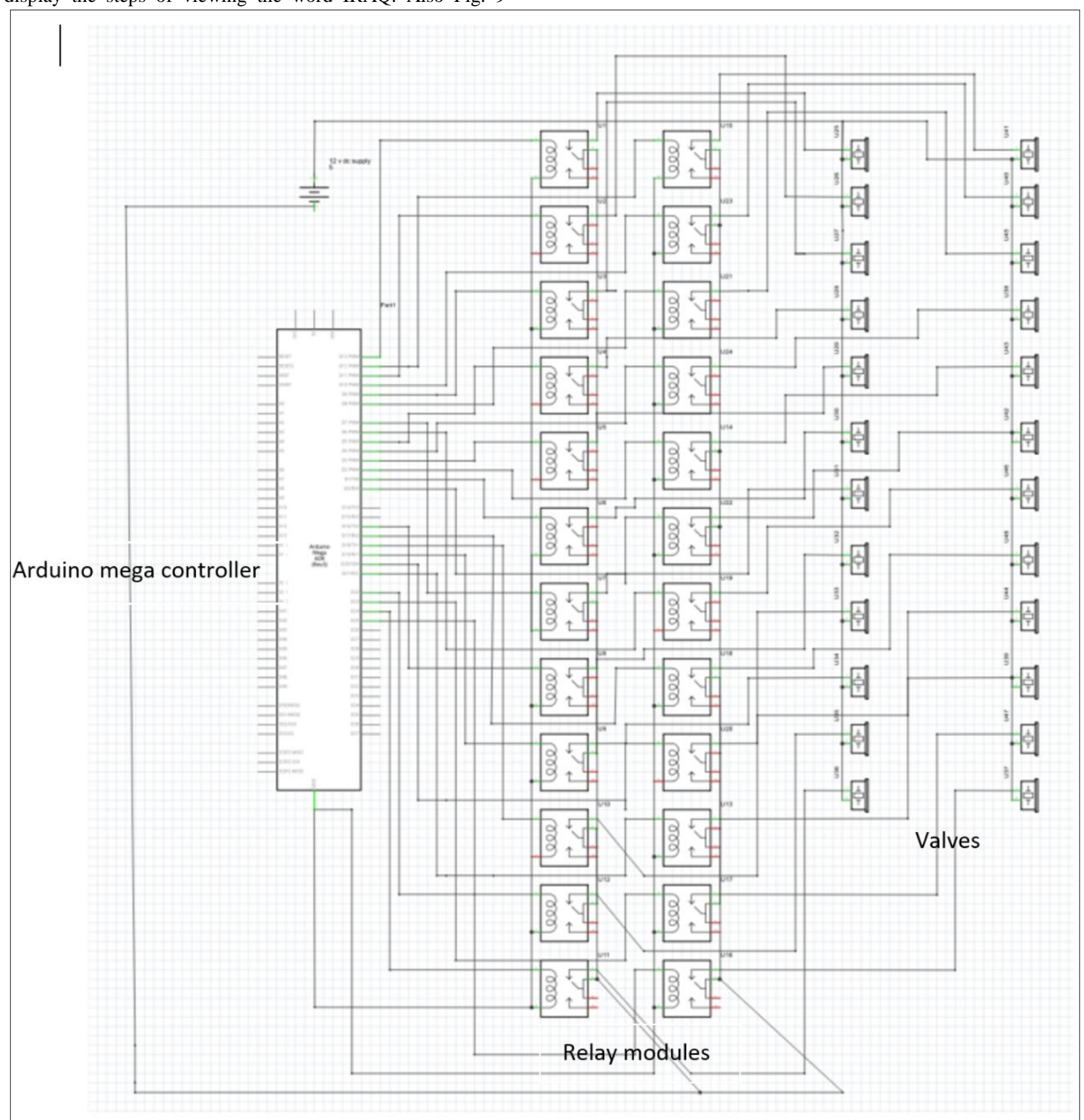

Fig.7. the schematic diagram of the proposed system.

\section{CONCLUSION}

Fountain design provides an excellent opportunity for multidisciplinary projects for engineering and art students. In this paper, detailed design of an indoor fountain with a special effect feature is presented to exemplify what can be done with fountains in educational settings. The result is simulated and repeated for different graphical shapes and different words and sentences. All the tested shapes and words show good viewing with accepted resolution. The fountain system is designed and tested with different speed in simulation form and also designed and tested in hardware system by changing the speed of sending the information to the control unit. This process leads to change the speed of switching the water valves. It is clear that in hardware design when the switching time is less than one second the resolution is minimize, because the flow of the water damage the style of movement. Also in software design we found that the best resolution at high speed is obtained when the distance from the computer increase. The using of 24 valve in hardware design give a good resolution for design different graphical shapes and as the number of valves increase the resolution also increase. 

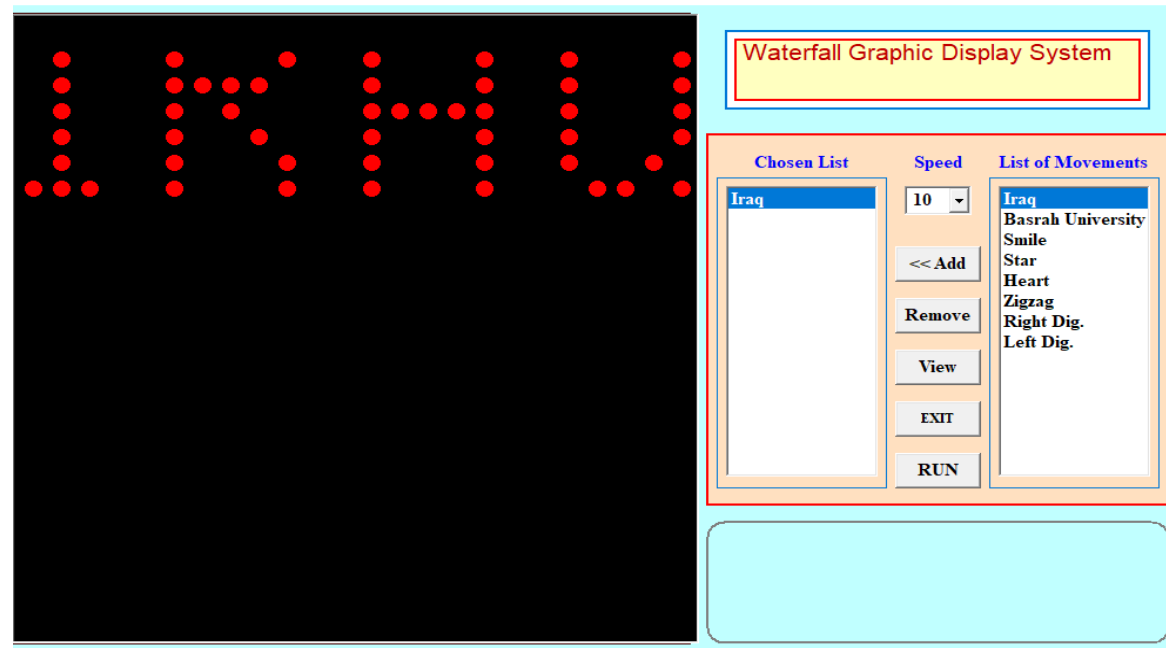

Waterfall Graphic Display System
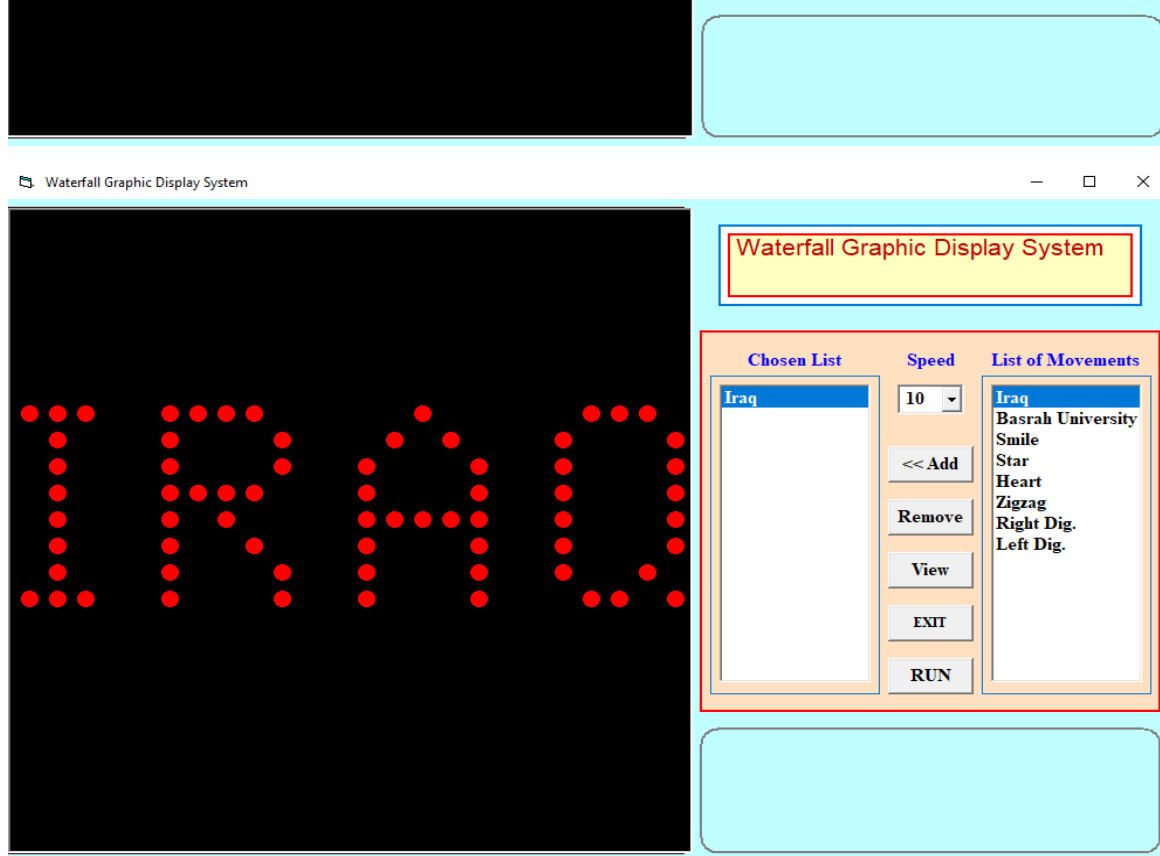

W. Waterfall Graphic Display System

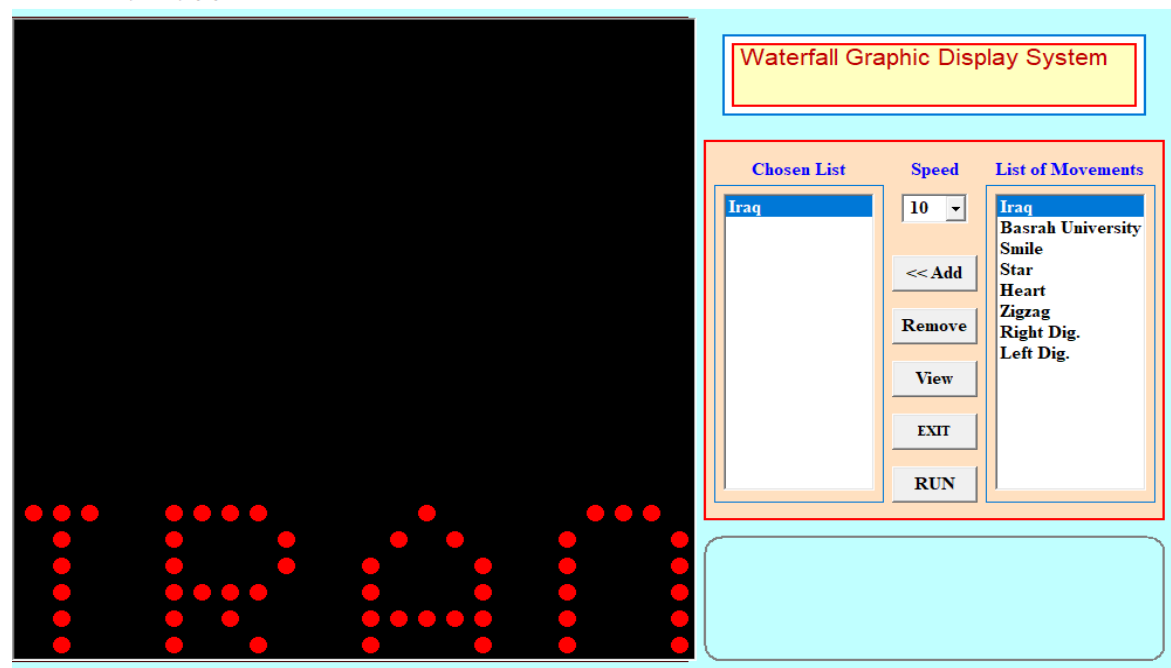

Fig.8.The steps of the IRAQ word movement 

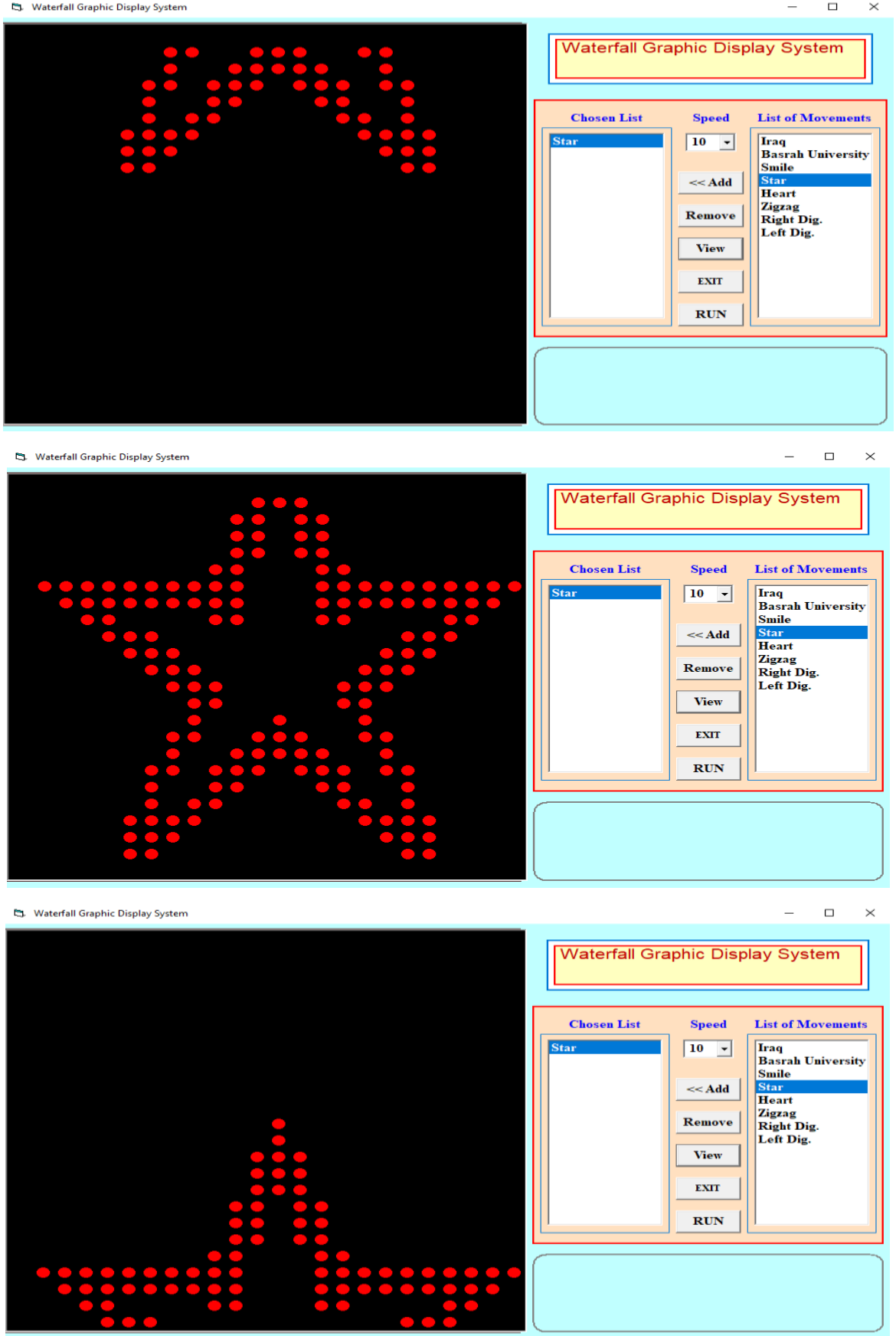

Fig.9.The steps of the star graphical shape movement

\section{REFERENCES}

[1] Paolo Visconti, Paolo Costantini and G. Cavalera, "Smart electronic system for dancing fountain control capable to create water and light scenarios synchronized with music track" ARPN Journal of Engineering and Applied Sciences, VOL. 11, NO. 9, MAY 2016.

[2] Said Shakrian, "Microcontrolled Water Fountain: A Multidisciplinary Project" Int. J. Engng Ed. Vol. 20, No. 4, pp. 654-659, 2004.

[3] Philippe Prévot, "Histoire des jardins" ISBN: 2879017149, Editions Sud Ouest, Bordeaux, 2006.

[4] Paul H. Dietz, Gabriel Reyes, and David Kim, " The Pump Spark Fountain Development Kit", Design Methods, pp. 21-25, 2014.
[5] Said Shakerin, "water fountains blend art and engineering: a resource for engineering education" Proceedings of the 2004 American Society for Engineering Education Annual Conference \& Exhibition, 2004.

[6] Adrian Hanson, Salim Bawazir, Kenneth Steven, "Teaching introductory fluids through fountain design" 3rd ASEE/IEEE Frontiers in Education Conference S3B9, November 5-8, 2003.

[7] George Thomson, Nick Wilson " Assessing public outdoor drinking fountain prevalence and quality: Using outdoor field observation in playgrounds "University of Otago, Wellington August 2017.

[8] Tommi Kuikka "Water fountains in the worldscape" International Water History Association and KehräMedia 
Inc., 2012.

[9] Juuti p., Antoniou G., Dragoni W., El-Gohary F., Feo G., Katko T., Rajala R., Zheng X., Drusiani R. and Angelakis A., " Short Global History of Fountains", water, Vol.7, No.5, pp. 2314-2348, 2015.

[10] A. T. Rashid and O. T. Rashid, “ Design and Implementation a Smart Energy Saving System using an Arduino and RF Module, International Journal of Computer Applications (0975 - 8887) Volume 182 - No. 26, November- 2018

[11] F. K. Handhal and A. T. Rashid, "Design and building a single-phase smart energy meter using Arduino and RF communication system", Proc. of the 3rd Int. Sci. Conf. (14-15/march/2018).

[12] F. K. Handhal and A. T. Rashid, “ Design And Building A Single-Phase Smart Energy Meter Using Arduino And RF Communication System Journal of Al-Nisour University Collage, Vol. 6 pp. 204-2011, 2018.

[13] Bellagio- Las Vegas Hotels. http://www.bellagio.com/, retrieved 1/14/2014.

[14] World of Color- Wikipedia. http://en.wikipedia.org/wiki/World_of_Color, retrieved $1 / 19 / 2014$

[15] D"oring, T., Sylvester, A., and Schmidt, A. A Design Space for Ephemeral User Interfaces. In Proceedings of the 7th International Conference on Tangible, Embedded and Embodied Interaction, TEI '13, ACM (New York, NY, USA, 2013), 75-82.

[16] Koei Co., Ltd. http://www.koeiaquatec.co.jp/, retrieved $1 / 12 / 2014$

[17] Bit.Fall - Science Gallery. https:// dublin.sciencegallery.com/surfacetension/ bitfall /, retrieved 1/19/2014.

[18] Heiner, J. M., Hudson, S. E., and Tanaka, K. The Information Percolator: Ambient Information Display in a Decorative Object. In Proceedings of the 12th Annual ACM Symposium on User Interface Software and Technology, UIST '99, ACM (New York, NY, USA, 1999), 141-148

[19] Sylvester, A., D"oring, T., and Schmidt, A. Liquids, Smoke, and Soap Bubbles: Reflections on Materials for Ephemeral User Interfaces. In Proceedings of the Fourth International Conference on Tangible, Embedded, and Embodied Interaction, TEI '10, ACM (New York, NY, USA, 2010), 269-270.

[20] Par'es, N., Durany, J., and Carreras, A. Massive Flux
Design for an Interactive Water Installation: Water Games. In Proceedings of the 2005 ACM SIGCHI International Conference on Advances in Computer Entertainment Technology, ACE '05, ACM (New York, NY, USA, 2005), 266-269.

[21] Hoste, L., and Signer, B. Water Ball Z: An Augmented Fighting Game Using Water as Tactile Feedback. In Proceedings of the 8th International Conference on Tangible, Embedded and Embodied Interaction, TEI '14, ACM (New York, NY, USA, 2013), 173-176.

[22] Casual Profanity. http:// casualprofanity.com/, retrieved $1 / 19 / 2014$.

[23] Dietz, P. H., Han, J. Y., Westhues, J., Barnwell, J., and Yerazunis, W. Submerging Technologies. In ACM SIGGRAPH 2006 Sketches, SIGGRAPH '06, ACM (New York, NY, USA, 2006).

[24] Sato, M., Poupyrev, I., and Harrison, C. Touch'e: Enhancing Touch Interaction on Humans, Screens, Liquids, and Everyday Objects. In Proceedings of the SIGCHI Conference on Human Factors in Computing Systems, CHI '12, ACM (New York, NY, USA, 2012), 483-492.

[25] Mann, S., Janzen, R., and Huang, J.” water Touch": An Aquatic Interactive Multimedia Sensory Table Based on Total Internal Reflection in Water. In Proceedings of the 19th ACM International Conference on Multimedia, MM '11, ACM (New York, NY, USA, 2011), 925-928.

[26] Takahashi, Y., Matoba, Y., and Koike, H. Fluid Surface: Interactive Water Surface Display for Viewing Information in a Bathroom. In Proceedings of the 2012

[27] Tao, J., Geng, Z., and Fan, Q. A Digitized Water Display System Based on RS-422 Bus. In Electrical and Control Engineering (ICECE), 2010.

[28] Mann, S., Janzen, R., and Post, M. Hydraulophone Design Considerations: Absement, Displacement, and Velocity-sensitive Music Keyboard in Which Each Key is a Water Jet. In Proceedings of the 14th Annual ACM International Conference on Multimedia, MULTIMEDIA '06, ACM (New York, NY, USA 2006), 519-528.

[29] Mann, S., Janzen, R., Huang, J., Kelly, M., Ba, L. J., and Chen, A. User-interfaces based on the Water-hammer Effect: Water-hammer Piano as an Interactive Percussion Surface. In Proceedings of the Fifth International Conference on Tangible, Embedded, and Embodied Interaction, TEI '11, ACM (New York, NY, USA, 2011), $1-8$ 